\title{
Statin Therapy before Cardiac Surgery: Neutral or Detrimental Effects
}

\author{
Putzu, Alessandro ; Gallo, Michele ; Ferrari, Enrico ; Cassina, Tiziano ; Landoni, Giovanni
}

DOI: https://doi.org/10.1097/ALN.0000000000002061

Posted at the Zurich Open Repository and Archive, University of Zurich

ZORA URL: https://doi.org/10.5167/uzh-158753

Journal Article

Published Version

Originally published at:

Putzu, Alessandro; Gallo, Michele; Ferrari, Enrico; Cassina, Tiziano; Landoni, Giovanni (2018). Statin Therapy before Cardiac Surgery: Neutral or Detrimental Effects. Anesthesiology, 128(3):685-686.

DOI: https://doi.org/10.1097/ALN.0000000000002061 
surgery: A randomized controlled trial. ANESTHESIOLOGY 2017; 127:36-49

2. Navarro LH, Bloomstone JA, Auler JO Jr, Cannesson M, Rocca GD, Gan TJ, Kinsky M, Magder S, Miller TE, Mythen M, Perel A, Reuter DA, Pinsky MR, Kramer GC: Perioperative fluid therapy: A statement from the International Fluid Optimization Group. Perioper Med (Lond) 2015; 4:3

3. Thiele RH, Raghunathan K, Brudney CS, Lobo DN, Martin D, Senagore A, Cannesson M, Gan TJ, Mythen MM, Shaw $\mathrm{AD}$, Miller TE; Perioperative Quality Initiative (POQI) I Workgroup: American Society for Enhanced Recovery (ASER) and Perioperative Quality Initiative (POQI) joint consensus statement on perioperative fluid management within an enhanced recovery pathway for colorectal surgery. Perioper Med (Lond) 2016; 5:24

4. Pearse RM, Harrison DA, MacDonald N, Gillies MA, Blunt M, Ackland G, Grocott MP, Ahern A, Griggs K, Scott R, Hinds C, Rowan K; OPTIMISE Study Group: Effect of a perioperative, cardiac output-guided hemodynamic therapy algorithm on outcomes following major gastrointestinal surgery: A randomized clinical trial and systematic review. JAMA 2014; 311:2181-90

5. Pearse R, Dawson D, Fawcett J, Rhodes A, Grounds RM, Bennett ED: Early goal-directed therapy after major surgery reduces complications and duration of hospital stay. A randomised, controlled trial [ISRCTN38797445]. Crit Care 2005; 9:R687-93

6. Gan TJ, Soppitt A, Maroof M, el-Moalem H, Robertson KM, Moretti E, Dwane P, Glass PS: Goal-directed intraoperative fluid administration reduces length of hospital stay after major surgery. ANESTHESIOLOGY 2002; 97:820-6

7. Feldheiser A, Conroy P, Bonomo T, Cox B, Garces TR, Spies C Anaesthesia Working Group of the Enhanced Recovery After Surgery (ERAS®) Society; Enhanced Recovery After Surgery Society: Development and feasibility study of an algorithm for intraoperative goal-directed haemodynamic management in noncardiac surgery. J Int Med Res 2012; 40:1227-41

8. Hamilton-Davies C, Mythen MG, Salmon JB, Jacobson D, Shukla A, Webb AR: Comparison of commonly used clinical indicators of hypovolaemia with gastrointestinal tonometry. Intensive Care Med 1997; 23:276-81

9. Hahn RG, Lyons G: The half-life of infusion fluids: An educational review. Eur J Anaesthesiol 2016; 33:475-82

10. Lobo DN, Bostock KA, Neal KR, Perkins AC, Rowlands BJ, Allison SP: Effect of salt and water balance on recovery of gastrointestinal function after elective colonic resection: A randomised controlled trial. Lancet 2002; 359:1812-8

11. Tengberg LT, Bay-Nielsen M, Bisgaard T, Cihoric M, Lauritsen ML, Foss NB; AHA study group: Multidisciplinary perioperative protocol in patients undergoing acute high-risk abdominal surgery. Br J Surg 2017; 104:463-71

12. Hamilton MA, Cecconi M, Rhodes A: A systematic review and meta-analysis on the use of preemptive hemodynamic intervention to improve postoperative outcomes in moderate and high-risk surgical patients. Anesth Analg 2011; 112:1392-402

13. Rollins KE, Lobo DN: Intraoperative goal-directed fluid therapy in elective major abdominal surgery: A meta-analysis of randomized controlled trials. Ann Surg 2016; 263:465-76

14. Feldheiser A, Aziz O, Baldini G, Cox BP, Fearon KC, Feldman LS Gan TJ, Kennedy RH, Ljungqvist O, Lobo DN, Miller T, Radtke FF, Ruiz Garces T, Schricker T, Scott MJ, Thacker JK, Ytrebø LM Carli F: Enhanced Recovery After Surgery (ERAS) for gastrointestinal surgery, part 2: Consensus statement for anaesthesia practice. Acta Anaesthesiol Scand 2016; 60:289-334

15. Chappell D, Jacob M, Hofmann-Kiefer K, Conzen P, Rehm M: A Rational Approach to Perioperative Fluid Management. ANESTHESIOLOGY 2008; 109:723-40

(Accepted for publication November 27, 2017.)

\section{Statin Therapy before Cardiac Surgery: Neutral or Detrimental Effects?}

\section{To the Editor:}

We read the interesting large retrospective study by Komatsu et al. on preoperative chronic statin use in patients undergoing coronary artery bypass grafting, valve surgery, or combined procedures. ${ }^{1}$ Chronic statin therapy was associated with no significant difference in prolonged mechanical ventilation, pneumonia, in-hospital mortality, neurologic outcome, and length of intensive care unit or hospital stay, ${ }^{1}$ suggesting neutral effects on postoperative clinical outcome.

It would be interesting to know the incidence of acute kidney injury after surgery in the study by Komatsu et al. ${ }^{1} \mathrm{It}$ is well known that postoperative acute kidney injury is crucial in patients' postoperative course and is associated with higher mortality rate. ${ }^{2}$ Two large, high-quality, randomized placebo-controlled trials were recently published, respectively, in the New England Journal of Medicine and JAMA. Zheng et al. ${ }^{3}$ randomly assigned 1,922 cardiac surgery patients to receive perioperative rosuvastatin or placebo, started 1 to 8 days before surgery, and the authors found that perioperative statins did not prevent postoperative atrial fibrillation or perioperative myocardial damage, but acute kidney injury was more common in patients receiving rosuvastatin. Billings et $a ._{.}{ }^{4}$ randomized 617 patients to high-dose perioperative atorvastatin or placebo, started the day before surgery, and found increased acute kidney injury in statin-naive patients with chronic kidney disease. A recent systematic review and meta-analysis of randomized controlled trials with low risk of bias found that perioperative statin therapy was associated with an increased incidence of postoperative acute kidney injury as compared with placebo, with 314 of 1,318 patients $(23.82 \%)$ in the statin group having acute kidney injury versus 262 of 1,319 patients $(19.86 \%)$ in the placebo group (odds ratio 1.26 [95\% CI, 1.05 to 1.52 ]; $P=0.01) .{ }^{5}$ Notably, a trend toward increased mortality was noted in the statin group: 9 of $1,318(0.68 \%)$ patients died in the statin group versus 2 of $1,319(0.15 \%)$ in the placebo group (odds ratio 1.26 [95\% CI, 1.05 to 1.52 ]; $P=0.06) .5$ Since the trials included in the meta-analysis randomized patients to a short course of preoperative statin regimen (between 1 and 7 days), we would like to ask Komatsu et al. for further data regarding length of preoperative statin therapy and, if available, a stratification according to it (e.g., short-term vs. long-term statins administration).

In conclusion, there is growing high-quality evidence ${ }^{3-5}$ that suggests not administering statins in the days before cardiac surgery. Statins in the days before cardiac surgery are not

This letter was sent to the author of the original article referenced above, who did not respond.-Evan D. Kharasch, M.D., Ph.D., Editor-in-Chief 
only unuseful, as also suggested by the observational study of Komatsu et al. ${ }^{1}$ but are harmful to renal function, ${ }^{2-4}$ and a detrimental effect on survival could not be excluded. ${ }^{4}$ There is compelling need for further large, high-quality, randomized placebo-controlled trials to confirm these findings and to assess the most appropriate time-point of statin discontinuation before cardiac surgery.

\section{Competing Interests}

The authors declare no competing interests.

Alessandro Putzu, M.D., Michele Gallo, M.D., Enrico Ferrari, M.D., Tiziano Cassina, M.D., Giovanni Landoni, M.D. Fondazione Cardiocentro Ticino, Lugano, Switzerland (A.P.). alessandroputzu@ymail.com

\section{References}

1. Komatsu R, Yilmaz HO, You J, Bashour CA, Rajan S, Soltesz EG, Sessler DI, Turan A: Lack of association between preoperative statin use and respiratory and neurologic complications after cardiac surgery. ANESTHESIOLOGY 2017; 126:799-809

2. Karkouti K, Wijeysundera DN, Yau TM, Callum JL, Cheng DC, Crowther M, Dupuis JY, Fremes SE, Kent B, Laflamme C, Lamy A, Legare JF, Mazer CD, McCluskey SA, Rubens FD, Sawchuk C, Beattie WS: Acute kidney injury after cardiac surgery: Focus on modifiable risk factors. Circulation 2009; 119:495-502

3. Zheng Z, Jayaram R, Jiang L, Emberson J, Zhao Y, Li Q, Du J, Guarguagli S, Hill M, Chen Z, Collins R, Casadei B: Perioperative rosuvastatin in cardiac surgery. $N$ Engl $\mathrm{J}$ Med 2016; 374:1744-53

4. Billings FT IV, Hendricks PA, Schildcrout JS, Shi Y, Petracek MR, Byrne JG, Brown NJ: High-dose perioperative atorvastatin and acute kidney injury following cardiac surgery: A randomized clinical trial. JAMA 2016; 315:877-88

5. Putzu A, Capelli B, Belletti A, Cassina T, Ferrari E, Gallo M Casso G, Landoni G: Perioperative statin therapy in cardiac surgery: A meta-analysis of randomized controlled trials. Crit Care 2016; 20:395

(Accepted for publication November 30, 2017.)

\section{Neurocritical Care Needs Predictive Scores That Succeed at Predicting Failure as Well as They Predict Success}

\section{To the Editor:}

In the August 2017 issue of Anesthesiology, Asehnoune et al. report their derivation of a novel bedside scoring system to predict extubation success in the intubated brain-injured patient. ${ }^{1}$ Many brain-injured patients are likely exposed to excess ventilated days because they do not meet extubation criteria originally established in general intensive care unit (ICU) populations. ${ }^{2}$ Careful consideration is required, however, before routinely utilizing new extubation prognostication scores. Although the VISAGE (visual pursuit, swallowing, age, Glasgow coma scale for extubation) score performs well at predicting extubation success based on favorable neurologic indicators, it does not adequately predict which patients will fail extubation due to neurologic dysfunction.

Recovery of arousal and airway protective reflexes after neurologic injury often is slow, and a subset of patients will benefit from early tracheostomy without an extubation attempt. The VISAGE score poorly discriminates extubation success among patients with low scores. Based on this model, a patient under $40 \mathrm{yr}$ old without visual pursuit or swallowing efforts, and with a Glasgow coma scale less than 10 , would have an almost $60 \%$ chance of extubation success. Barring a prediction of rapid neurologic improvement or barriers to safe reintubation, we believe that this individual should undergo a trial extubation. We are concerned that adoption of a scoring system with explicit or perceived cut-points would lead to such patients remaining intubated longer than necessary. A similar problem arises from the predictive score introduced in ANESTHEsIology earlier this year by Godet et al. ${ }^{3}$ Although their regressionbased score has a clear inflection point, fully one third of patients below this score were successfully extubated. At the suggested cut-point, their score falls short of the degree of negative predictive value originally reported for the Rapid Shallow Breathing Index (RSBI) in a general ICU population. ${ }^{4}$ The negative predictive value for the VISAGE score at a cut-point of 3 performs even worse.

Timely extubation of all ICU patients, including those with brain injury, helps prevent ventilator-associated complications. Although our colleagues highlight that brain-injured patients can be safely extubated, we caution against rigorously applying these scores due to the possibility of excess mechanical ventilation for patients who score poorly. Extubation failure and reintubation is certainly not without risk and is predictive of worse outcomes, though causality has not been established. ${ }^{1,5}$ Further development of scoring models with improved negative predictive values is needed to identify patients who should truly forgo trial extubation. Until these risks are further quantified, and such a tool is developed, the neurocritical care intensivist will necessarily have to tolerate and manage higher reintubation rates than those seen in a general ICU population.

\section{Competing Interests}

The authors declare no competing interests.

Johann Patlak, M.D., Shahzad Shaefi, M.D., Lauren Buhl, M.D., Ph.D., Myles D. Boone, M.D. Beth Israel Deaconess Medical Center, Boston, Massachusetts (J.P.). jpatlak@bidmc.harvard.edu

\section{References}

1. Asehnoune K, Seguin P, Lasocki S, Roquilly A, Delater A, Gros A, Denou F, Mahé PJ, Nesseler N, Demeure-Dit-Latte D, 